\title{
Research on Deformation and Force of Bridge Pile Foundation on High and Steep Slope in Mountainous Area
}

\author{
Mingyue Zhang, Hao Luo \\ Shanghai Maritime University, Shanghai, China \\ Email: 1434478896@qq.com, 527338857@qq.com
}

How to cite this paper: Zhang, M.Y. and Luo, H. (2020) Research on Deformation and Force of Bridge Pile Foundation on High and Steep Slope in Mountainous Area. World Journal of Engineering and Technology, 8, 551-564.

https://doi.org/10.4236/wjet.2020.83039

Received: August 7, 2020

Accepted: August 28, 2020

Published: August 31, 2020

Copyright $\odot 2020$ by author(s) and Scientific Research Publishing Inc. This work is licensed under the Creative Commons Attribution International License (CC BY 4.0).

http://creativecommons.org/licenses/by/4.0/

\begin{abstract}
With the rapid development of my country's economy, the demand for infrastructure construction is also increasing. However, in most areas of China, the terrains are mountainous and hilly. Some projects have to be built on steep slopes. Choosing viaducts or half-bridges on high-steep slopes is not only conducive to the protection of the surrounding environment, but also conducive to the stability of the slope. Bridges usually choose the form of pile foundation-high pier bridge. This paper uses numerical simulation to study and analyze the bridge pile foundation of the slope section. Relying on actual engineering, use the finite element software ABAQUS6.14 to establish a three-dimensional finite element model to study the bearing mechanism and mechanical characteristics of the pile foundation under vertical load, horizontal load and inclined load, discuss the influence of the nature of the soil around the pile and the stiffness of the pile body on the deformation and internal force of the bridge pile foundation in the slope section. The analysis results show that the horizontal load has a great influence on the horizontal displacement of the pile, but has a small influence on the vertical displacement, and the vertical load is just the opposite. Inclined load has obvious "p- $\Delta$ " effect. The increase in soil elastic modulus and pile stiffness will reduce the displacement of the pile foundation, but after reaching a certain range, the displacement of the pile foundation will tend to be stable. Therefore, in actual engineering, if the displacement of the pile foundation fails to meet the requirements, the hardness of the soil and the stiffness of the pile can be appropriately increased, but not blindly.
\end{abstract}

\section{Keywords}

High and Steep Slope, Bridge Pile Foundation, Force and Deformation Analysis, Influencing Factors 


\section{Introduction}

With the rapid economic development, the pace of China's infrastructure construction is getting faster and faster. Especially in recent years, the country is vigorously developing mountainous areas. Most areas of China are mountainous and hilly. Some projects, such as railway and highway projects, must be adopted the structural forms of viaducts or half-roads and half-bridges, as well as projects across rivers and mountains, are found everywhere. Therefore, these situations lead to the need to build some pile foundations on high and steep slopes. The force and bearing characteristics of this type of pile foundation are very complicated. The bridge pile foundation on the slope cannot be simply regarded as the pile foundation on the flat ground, nor can it be regarded as the anti-slide pile.

At present, many scholars at home and abroad have done a lot of work on the bearing characteristics and bearing mechanism of bridge pile foundations on high and steep slopes. Among them, Zhao Minghua's research group has made many valuable research results. Bi Jihong [1] used the finite element software ANSYS to analyze the impact of vehicle braking on the slope, and divided the braking action into different working conditions for simulation, and obtained its impact on the slope pile foundation. Guo Yongjian, Xie Yongli, Jiang Li et al. [2] obtained through laboratory experiments and studies that end-bearing piles and friction piles behave similarly when the lateral load is small, and the vertical load has a greater impact on the friction pile. Lin Pengzhen, Wu Fahui, and Yang Zijiang [3] studied the influence of lateral load on the pile foundation of the slope and the stress characteristics of the slope with multiple bottom layers. Using finite element software to analyze, the results show that the front resistance of the slope has a great influence on the displacement and stress of the pile body. At the boundary of the soil layer, the displacement and stress of the pile foundation will change suddenly. Zhang Yongjie, Li Youjun, Zhao Minghua, etc. [4] proposed a calculation method for bridge pile foundations on high and steep slopes. This method improves the uneconomical and low safety factor of traditional methods. Feng Zhongju, Wang Hang, Wei Jin et al. [5] analyzed the influence of slope and pile length on the bearing mechanism of the pile foundation on the slope based on the independently developed test platform. Zhao Minghua, Yang Chaowei, Chen Yaohao, et al. [6] conducted field test research to summarize and analyze the field test data, including pile shaft force, pile side resistance and pile bending moment. Lin et al. [7] believed that in the process of studying the impact of scouring on bridge pile foundations, the previous methods ignored the impact of the stress history of the soil before and after scouring on the pile foundation.

In summary, most of the current researches focus on the force and deformation characteristics of pile foundations on flat ground, and there is a lack of systematic theoretical research on the load transfer mechanism of bridge pile foundations on slopes. Therefore, further research on the bridge pile foundation on the slope has great practical engineering value. 


\section{Model Establishment}

\subsection{Overview of the Model}

Literature [6] describes the field test study of the bridge pile foundation located at $\mathrm{K} 100+980-\mathrm{K} 105+800$ of Zhanghua Expressway. Based on the literature [6], through ABAQUS6.14, a calculation model was established. The model is 79 $\mathrm{m}$ long, $50 \mathrm{~m}$ high, with a slope of $45^{\circ}$, and a longitudinal extension of $40 \mathrm{~m}$ in the $\mathrm{z}$ direction. Both pile and column have circular cross-sections. The pile diameter is $2 \mathrm{~m}$, the pile length is $25 \mathrm{~m}$, and the pier height is $8.88 \mathrm{~m}$. Since this model is a completely symmetrical model, half of the model is used for calculation. The distribution of the soil around the pile and the size of the model is shown in Figure 1, the grid division of the model is shown in Figure 2, and the material properties of pile soil are shown in Table 1.

\subsection{Model Verification}

This article uses the model in the literature [6] for further analysis. On the basis of the literature test results, the finite element software ABAQUS6.14 is used for numerical simulation, and the rationality of the model and parameters selected in this paper is verified. The comparison between the calculation results and the test results is shown in Figure 3.

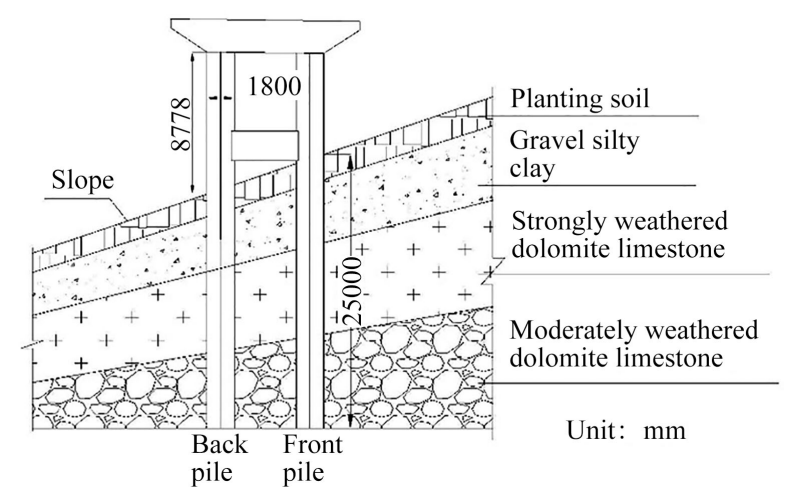

Figure 1. Soil distribution around the pile and model size.

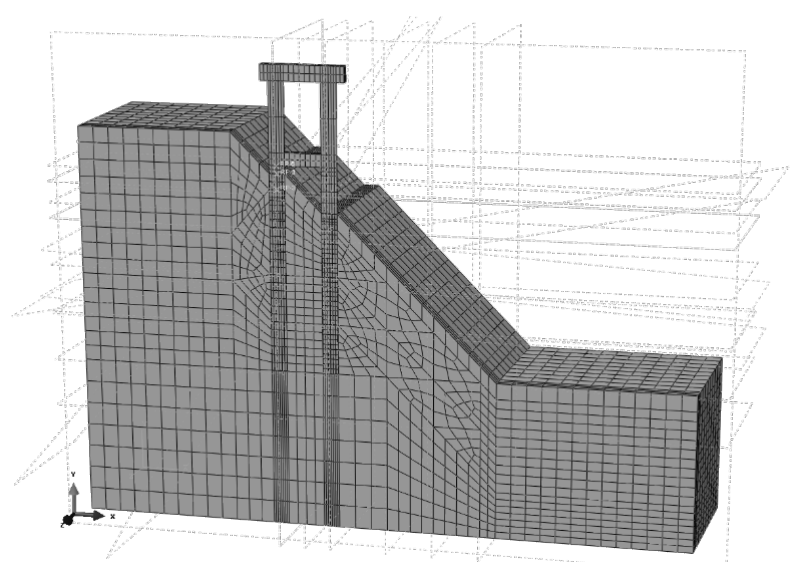

Figure 2. Model meshing. 


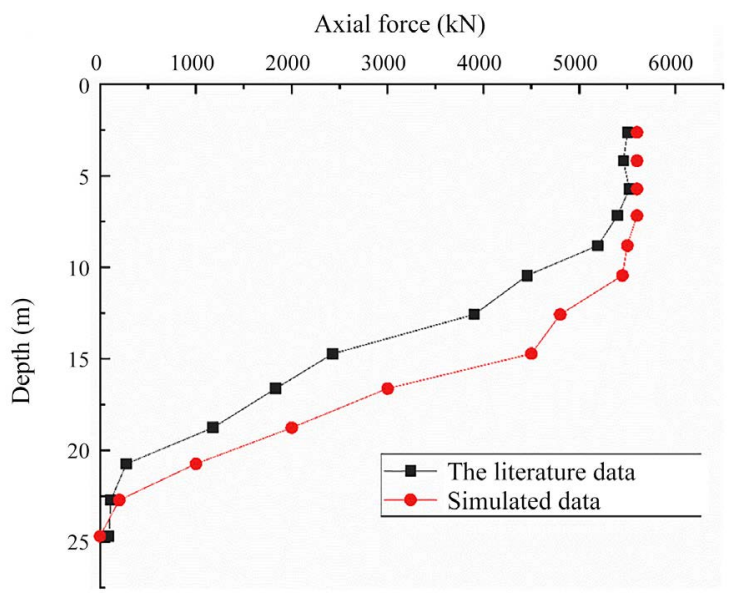

Figure 3. Verification result.

Table 1. Material parameters such as soil and piles.

\begin{tabular}{cccccc}
\hline Soil name & $\begin{array}{c}\text { Natural } \\
\text { density }\left(\mathrm{g} \cdot \mathrm{cm}^{-3}\right)\end{array}$ & $\begin{array}{c}\text { Characteristic } \\
\text { value of bearing } \\
\text { capacity (KPa) }\end{array}$ & $\begin{array}{c}\text { Elastic } \\
\text { Modulus (MPa) }\end{array}$ & $\begin{array}{c}\text { Cohesion } \\
(\mathrm{KPa})\end{array}$ & $\begin{array}{c}\text { Internal } \\
\text { friction angle } \\
\left({ }^{\circ}\right)\end{array}$ \\
\hline Pile & 2.60 & & 29,500 & & \\
Planting soil & 1.90 & 160 & 150 & 25 & 18 \\
$\begin{array}{c}\text { Gravel silty clay } \\
\text { Strongly weathered } \\
\text { dolomite limestone }\end{array}$ & 1.95 & 180 & 250 & 25 & 20 \\
$\begin{array}{c}\text { Moderately weathered } \\
\text { dolomite limestone }\end{array}$ & 2.15 & 380 & 3600 & 40 & 25 \\
\hline
\end{tabular}

\section{Simulation Results and Analysis}

\subsection{Single Vertical Load Action}

Assuming that other loads are zero, and vertical loads V (10 MPa, $20 \mathrm{MPa}, 30$ $\mathrm{MPa}, 40 \mathrm{MPa}, 50 \mathrm{MPa}, 60 \mathrm{MPa}$ ) are applied in stages to simulate the deformation and stress of the bridge pile foundation.

1) Analysis of pile foundation displacement

Figure 4(a) and Figure 4(b) show the vertical displacement of the front and rear piles along the pile body on a high and steep slope under different working conditions. The vertical compression curve of the pile foundation is basically linear. There is little difference between the vertical displacement of the front and rear piles. With the increase of the vertical load on the pile top, the vertical displacement of the pile body shows an increasing trend, and the large displacement of the pile foundation mainly occurs on the upper part of the pile body, and there is a very small displacement at the pile end, which indicates that the pile side of the pile foundation both the pile end and the pile end play a certain role. The upper load is first borne mainly by the pile side resistance. When the pile side resistance reaches the limit, then the pile side and the pile end are jointly borne. 


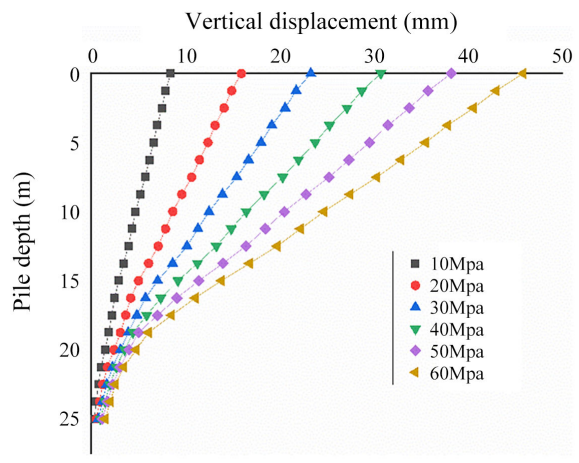

(a) Front pile

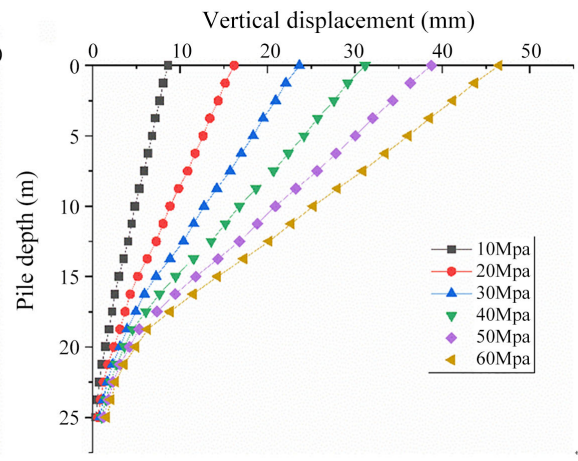

(b) Back pile

Figure 4. Vertical displacement of the pile under different working conditions.

Extract the load-displacement curve of the pile top under different working conditions as shown in Figure 5.

Figure 5(a) is the load-vertical displacement curve of the front and rear pile tops under different vertical loads. When the upper load varies from $10 \mathrm{MPa}$ to $60 \mathrm{MPa}$, the vertical displacement of the pile top is $8.62 \mathrm{~mm}, 16.19 \mathrm{~mm}, 23.65$ $\mathrm{mm}, 31.16 \mathrm{~mm}, 38.75 \mathrm{~mm}, 46.50 \mathrm{~mm}$, the latter five increased by $87.88 \%$, $174.34 \%, 261.54 \%, 349.51 \%$, and $439.40 \%$ respectively relative to the former. According to "Technical Specification for Testing of Building Foundation Piles" JGJ106-2014, the load corresponding to the settlement of the pile top $40 \mathrm{~mm}$ is taken as the vertical ultimate bearing capacity of the foundation, that is, when the load is about $50 \mathrm{MPa}$, it is the vertical ultimate bearing capacity of the pile foundation. Figure 5(b) shows the load-horizontal displacement curves of the front and rear pile tops under different working conditions. The load-horizontal displacement curves of the front and rear pile tops are basically linear. When the upper load varies from $10 \mathrm{MPa}$ to $60 \mathrm{MPa}$, the rear pile tops The horizontal displacement is $0.35 \mathrm{~mm}, 0.61 \mathrm{~mm}, 0.86 \mathrm{~mm}, 1.12 \mathrm{~mm}, 1.37 \mathrm{~mm}, 1.64 \mathrm{~mm}$, and the latter five are increased by $73.05 \%, 146.17 \%, 219.32 \%, 293.15 \%$, and $367.95 \%$ respectively. The horizontal displacement of the rear pile is larger than that of the front pile. Under a vertical load of $50 \mathrm{MPa}$, the horizontal displacement of the front pile is $0.37 \mathrm{~mm}$, and the horizontal displacement of the rear pile is 1.37 $\mathrm{mm}$. This is because of the slope, the length of the rear pile exposed to the soil is longer than that of the front pile, and the exposed part of the pile is not constrained by the rock and soil. The displacement of the rear pile is significantly greater than that of the front pile.

From the above analysis, it can be seen that the influence of the vertical load on the top of the pile on the vertical displacement is greater than the influence on the horizontal displacement. Therefore, the control of the vertical displacement is particularly important in the actual engineering mainly subject to vertical loads.

2) Analysis of internal force of pile foundation

Figure 6(a) and Figure 6(b) are diagrams of the axial force of the front and rear pile shafts under different working conditions. The overall axial force shows 


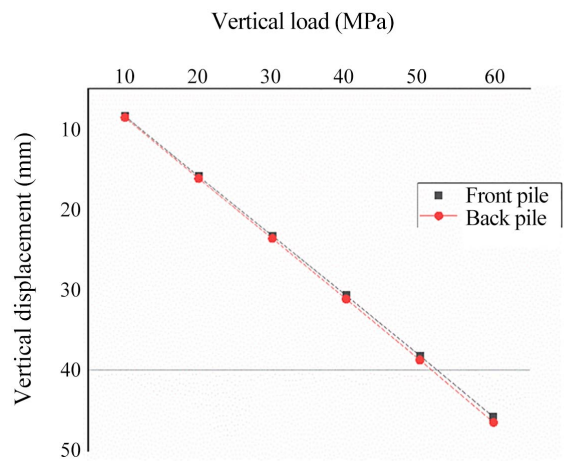

(a) Vertical displacement

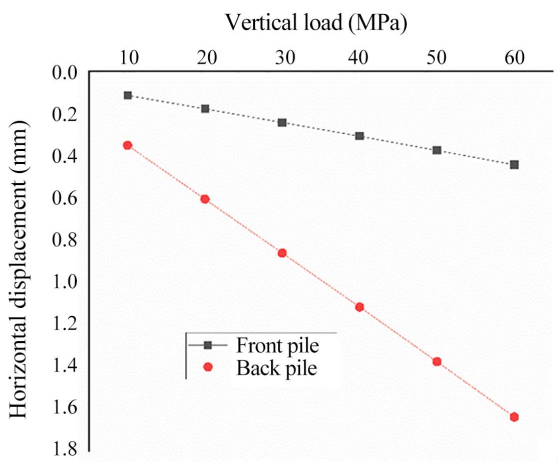

(b) Horizontal displacement

Figure 5. Load-displacement curves of front and rear piles under different working conditions.

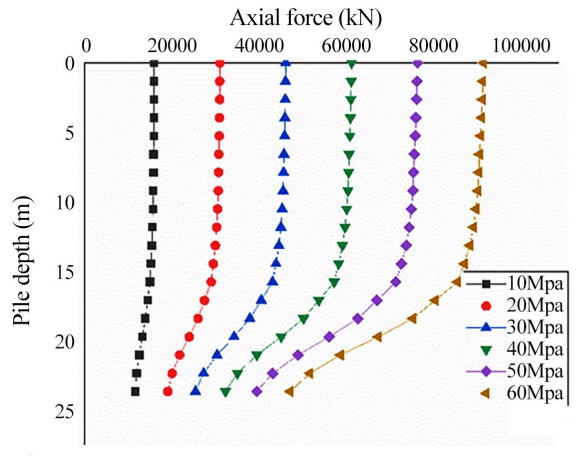

(a) Front pile

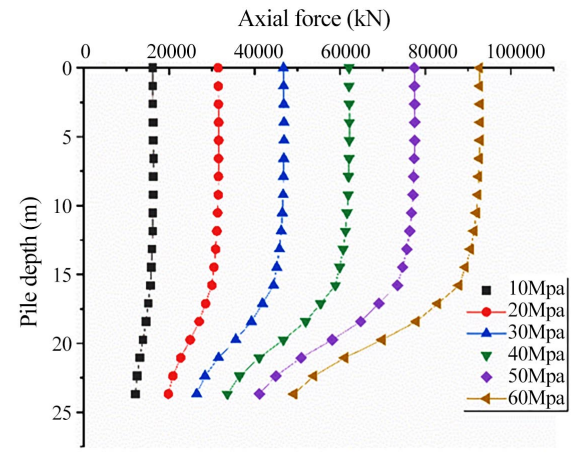

(b) Back pile

Figure 6. Pile shaft axial force under different working conditions.

a decreasing trend. Because the pile side resistance will offset part of the upper load and the pile foundation weight, the axial force will appear the pile tops decrease sequentially. The slope of the outer curve is greater than the slope of the internal test curve, indicating that the greater the load, the greater the relative displacement of the pile and soil, and the greater the pile side resistance. In the range of the buried depth of the pile foundation of $16 \mathrm{~m}$, the axial force decreases little, and the axial force begins to decrease at an accelerated rate below the buried depth of the pile foundation of $16 \mathrm{~m}$. For example, when the vertical load is $50 \mathrm{MPa}$ and the buried depth is $9 \mathrm{~m}$, the axial force is reduced by only $0.32 \%$. This is because on the high and steep slopes, the soil around the pile is no longer a semi-infinite space body, and the soil layer within the buried depth of $16 \mathrm{~m}$ does not fully exert the side friction resistance.

\subsection{Single Horizontal Load Effect}

Assuming that other loads are zero, horizontal loads $\mathrm{H}(330 \mathrm{kPa}, 660 \mathrm{kPa}, 990$ $\mathrm{kPa}, 1320 \mathrm{kPa}, 1650 \mathrm{kPa}, 1980 \mathrm{kPa}$ ) are applied in stages to simulate the deformation and stress of the bridge pile foundation.

1) Analysis of pile foundation displacement

Figure 7 shows the horizontal displacement of the front and rear pile founda- 
tions along the pile body under different horizontal loads. As the horizontal load increases, the horizontal displacement of the pile body increases. The front and rear double piles have different displacements. Under the same horizontal load, the horizontal displacement of the rear pile is greater than that of the front pile. Outside the range of $7.5 \mathrm{~m}$ buried depth of the front pile and $11 \mathrm{~m}$ of the buried depth of the rear pile, the maximum horizontal displacement of the pile body is $0.01 \mathrm{~mm}$, and the impact is almost negligible.

Figure 8 shows the load-horizontal displacement curve of the front and rear double-pile pile tops under different horizontal loads. The curve is basically linear. When the horizontal load is in the range of 330 to $1980 \mathrm{kPa}$, the offset of the front pile is: $2.01 \mathrm{~mm}, 4.03 \mathrm{~mm}, 6.04 \mathrm{~mm}, 8.04 \mathrm{~mm}, 10.0 \mathrm{~mm}, 12.05 \mathrm{~mm}$, and the latter five are increased by $101.57 \%$ and $202.16 \%, 302.01 \%, 401.63 \%$, and $502.49 \%$ respectively. It can be seen that the pile foundation is obviously affected by the horizontal load, and the large horizontal displacement should be avoided in the design work of the high and steep side bridge pile foundation.

2) Analysis of internal force of pile foundation

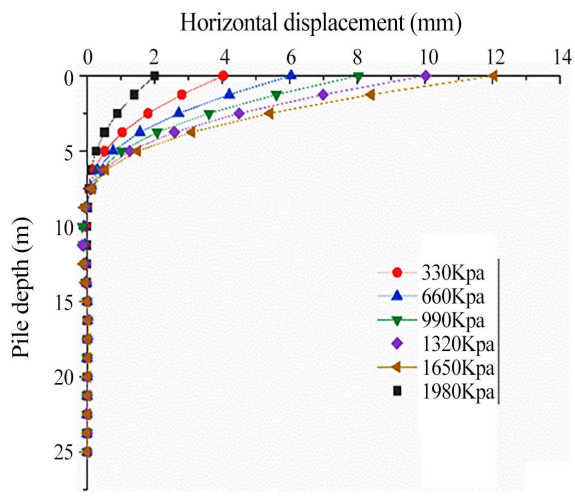

(a) Front pile

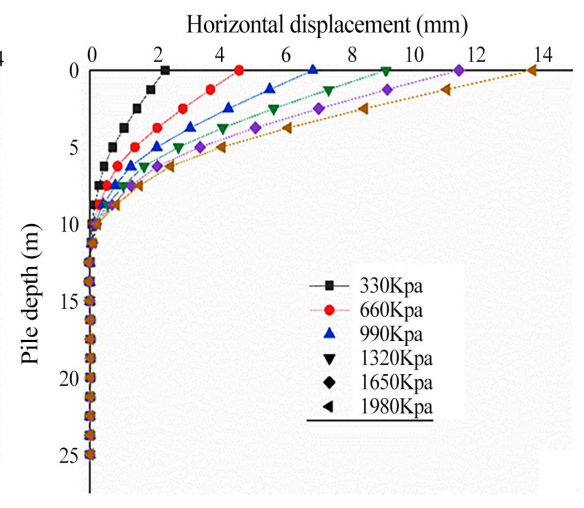

(b) Back pile

Figure 7. The horizontal displacement of the pile under different working conditions.

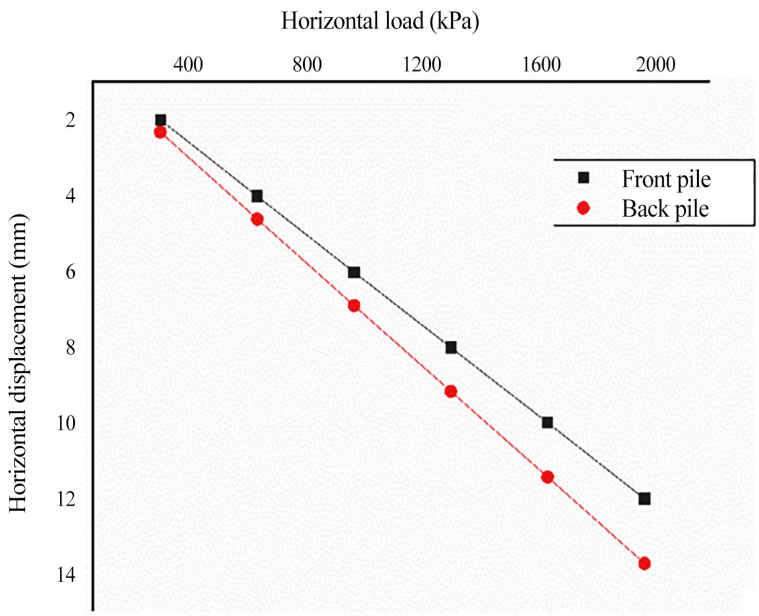

Figure 8. Load-displacement curve of the pile foundation before and after. 
It can be seen from Figure 9 that the bending moment first decreases along the pile body, then increases, then decreases, and finally tends to zero in the hard soil layer. The pile length ranges from 0 to $2.7 \mathrm{~m}$ for positive bending moment, below $2.7 \mathrm{~m}$ is for negative bending moment, and $2.7 \mathrm{~m}$ is right at the junction of soil layers. The bending moment increases as the horizontal load increases. When the horizontal load is within the range of 330 to $1980 \mathrm{kPa}$, the maximum bending moments are $254.5 \mathrm{kN} \cdot \mathrm{m}, 513.4 \mathrm{kN} \cdot \mathrm{m}, 772 \mathrm{kN} \cdot \mathrm{m}, 1030 \mathrm{kN} \cdot \mathrm{m}, 1289$ $\mathrm{kN} \cdot \mathrm{m}$, respectively, $1548 \mathrm{kN} \cdot \mathrm{m}$. Compared with the former, the latter five increased by $101.73 \%, 203.34 \%, 304.72 \%, 406.48 \%$, and $508.25 \%$ respectively.

\subsection{Inclined Load Effect}

Apply vertical load V (10 MPa, $20 \mathrm{MPa}, 30 \mathrm{MPa}, 40 \mathrm{MPa}, 50 \mathrm{MPa}, 60 \mathrm{MPa})$ and horizontal load H (330 kPa, $660 \mathrm{kPa}, 990 \mathrm{kPa}, 1320 \mathrm{kPa}, 1650 \mathrm{kPa}, 1980 \mathrm{kPa})$ to simulate the working conditions of bridge pile foundation under inclined load.

1) Analysis of pile foundation displacement

Figure 10(a) and Figure 10(b) show the vertical and horizontal displacements of the front pile under inclined loads. Figure 10(a) is similar to the displacement law when subjected to vertical load alone. The curve is basically linear, and the displacement is not much different. This shows that the horizontal load has a small effect on the vertical displacement. Figure 10(b) is different from the displacement when subjected to a horizontal load alone. The basic laws of the two curves are similar, but the sizes are different. For example, when the horizontal component load is $1980 \mathrm{kPa}$ and the pile depth is $1 \mathrm{~m}$, the displacement when subjected to horizontal load alone It is $8.40 \mathrm{~mm}$, and the displacement when subjected to an inclined load is $10.21 \mathrm{~mm}$.

It can be seen that the horizontal displacement under the inclined load is not a simple superposition of the vertical load and the horizontal displacement under the horizontal load, but has an obvious "p- $\Delta$ " effect (Buildings with relatively flexible lateral stiffness will produce a large horizontal displacement $\Delta$ under the action of wind load or horizontal earthquake. Because the structure is under the action of vertical load $\mathrm{P}$, the structure will further increase the lateral displacement value and cause the internal components of the structure to generate additional internal force). The existence of the "p- $\Delta$ " effect makes the inclined load act The horizontal displacement below is greater than the sum of the horizontal displacements of the two loads acting alone.

It can be seen from Figure 11 that under the action of inclined load, the vertical and horizontal displacements of the rear pile are larger than those of the front pile. This is because the rear pile has less soil in front of the pile, the length of the free section is longer, and the soil resistance is smaller. The horizontal and vertical displacement is greater.

Figure 12(a) and Figure 12(b) are the load-displacement curves of the pile top under various loading conditions. It can be seen from Figure 12(a) and Figure 12(b) that the size and regularity of the vertical displacement of the pile 
top under the condition of inclined load and single vertical load are very small and almost negligible. The change in the horizontal displacement of the pile top under various loading conditions is different from the vertical displacement of the pile top. The change in the horizontal displacement is very obvious. For example, when the horizontal component load is $1650 \mathrm{MPa}$, the horizontal displacement under a single vertical load is $0.37 \mathrm{~mm}$. The horizontal displacement is $10.03 \mathrm{~mm}$, and the horizontal displacement under inclined load is $13.15 \mathrm{~mm}$. The horizontal displacement of the inclined load increases by $26.4 \%$ relative to the superimposed displacement of the horizontal and vertical loads.

It can be seen that in actual engineering, the influence of the "p- $\Delta$ " effect on the pile foundation should be fully considered.

2) Analysis of internal force of pile foundation

Figure 13 shows the axial force of the front and rear piles under the oblique load. It can be seen that the distribution of the axial force is similar to that under a single vertical load. The axial force decreases slowly and then accelerates. The difference is the magnitude of the axial force on the top of the front and rear piles. As the inclined load increases, the upper load borne by the front pile is less than the upper load borne by the rear pile. For example, at an inclined load of 30 $\mathrm{MPa}, 990 \mathrm{kPa}$, the axial force on the top of the front pile is $43,140 \mathrm{kN}$, and the axial force of the rear pile top is $50,360 \mathrm{kN}$.

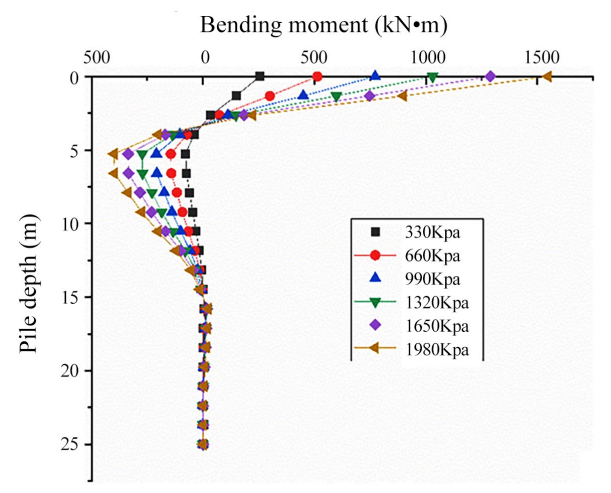

Figure 9. Bending moment of pile body.

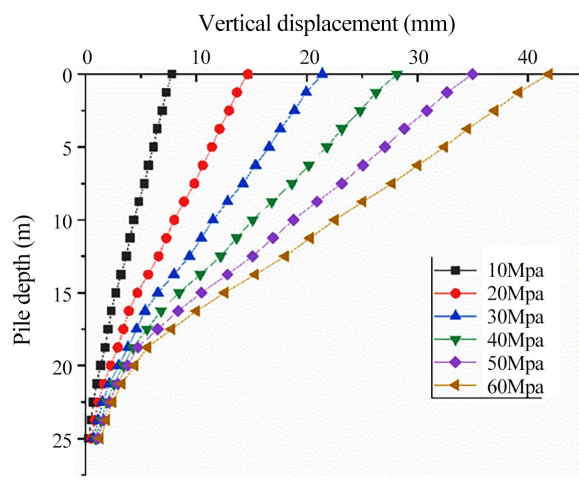

(a) Vertical displacement

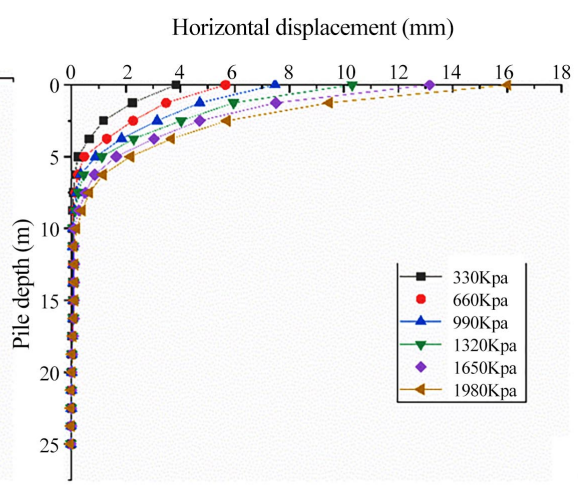

(b) Horizontal displacement

Figure 10. Pile body displacement under different working conditions. 


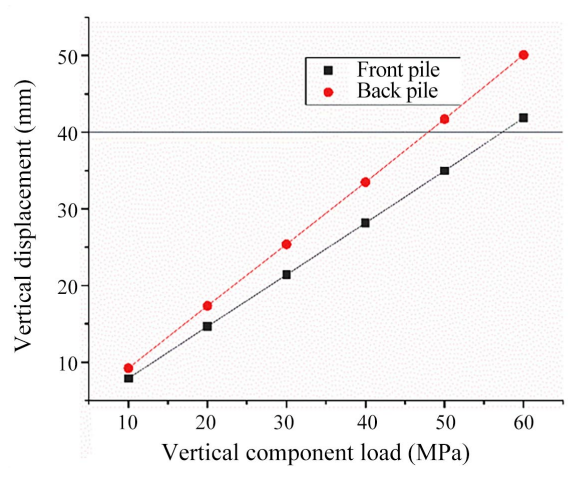

(a) Vertical displacement

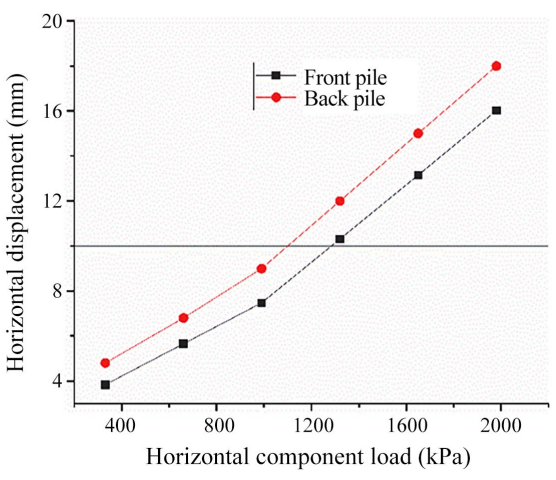

(b) Horizontal displacement

Figure 11. Load-displacement curve of the front and rear piles.

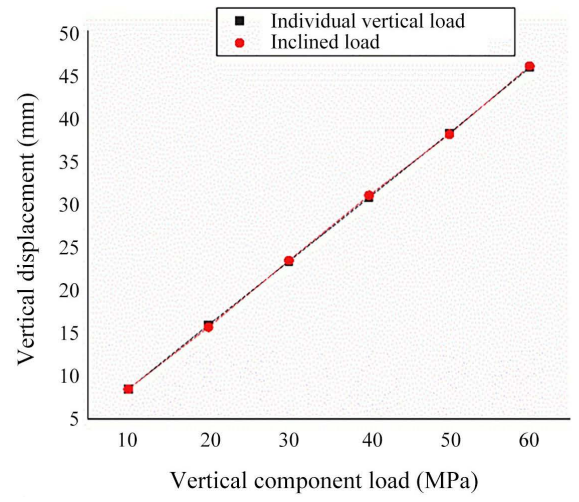

(a) Vertical displacement

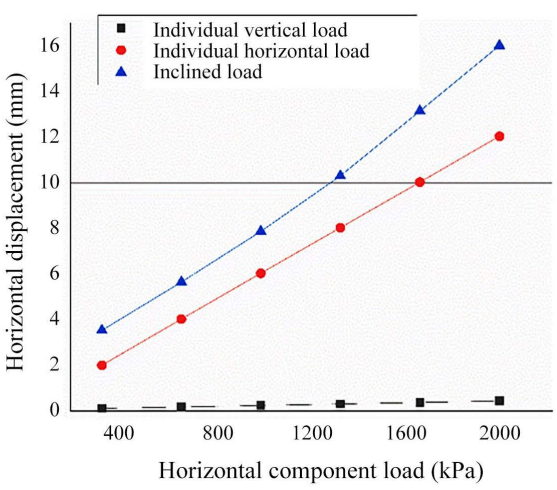

(b) Horizontal displacement

Figure 12. Displacement comparison of different loading conditions.

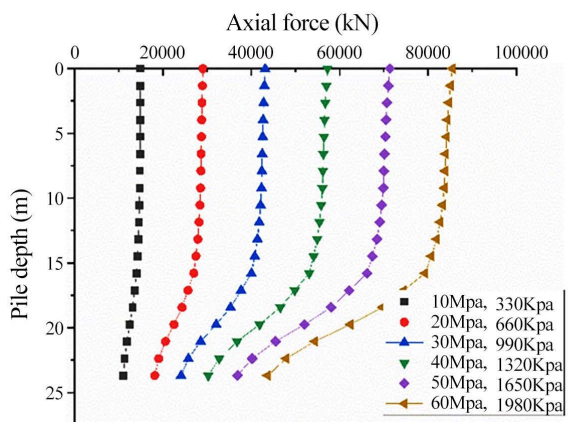

(a) Front pile

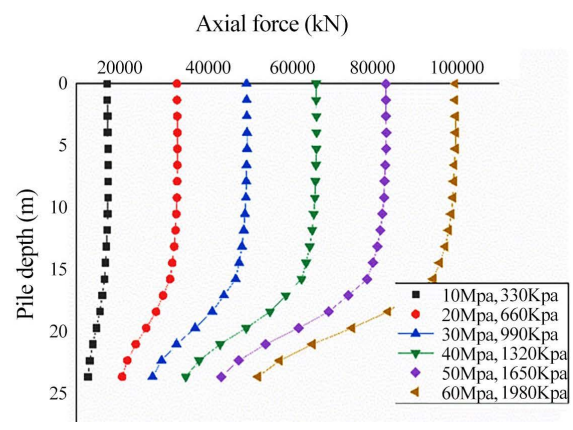

(b) Back pile

Figure 13. Pile shaft axial force.

\section{Analysis of Influencing Factors}

\subsection{The Influence of the Soil Properties around the Pile}

In the actual engineering of high-steep slope bridge pile foundation, the geological conditions are very complicated, and the elastic modulus of soil is often very different. Therefore, it is necessary to study the influence of soil performance on pile foundation, keep the other parameters of the model unchanged, take the soil elastic modulus $\mathrm{E}=0.25 \mathrm{E}, 0.5 \mathrm{E}, 1 \mathrm{E}$ and $2 \mathrm{E}$.

It can be drawn from Figure 14, Figure 15. 


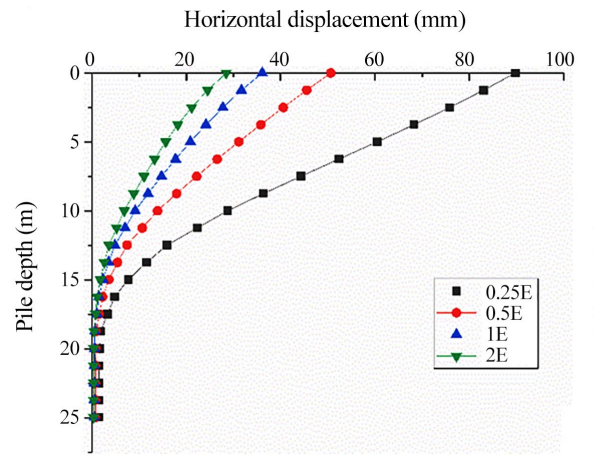

(a) Horizontal displacement

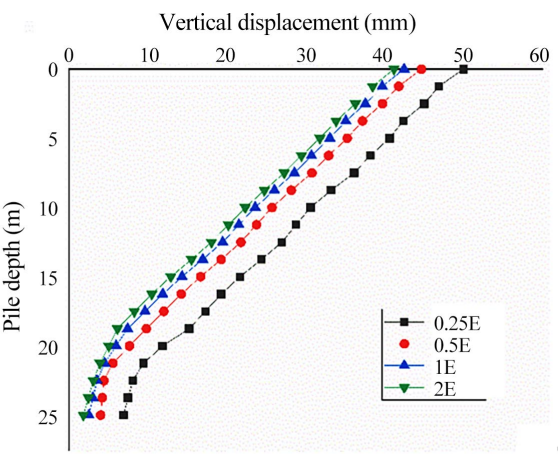

(b) Vertical displacement

Figure 14. Pile displacement under different soil elastic models.

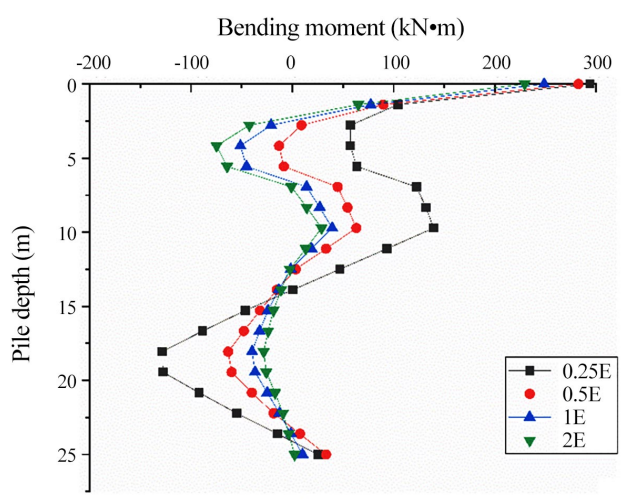

Figure 15. Pile bending moments of different soil elastic moduli.

1) The elastic modulus of the soil in the pile foundation of a high-steep slope bridge has a significant impact on the horizontal displacement of the pile foundation. For example, when the elastic modulus of the soil is within the range of $0.25 \mathrm{E}$ to $2 \mathrm{E}$, the horizontal displacements of the pile top are respectively 89.76 $\mathrm{mm}, 50.65 \mathrm{~mm}, 36.09 \mathrm{~mm}, 28.46 \mathrm{~mm}$, and the latter is reduced by $39.11 \mathrm{~mm}$, $14.56 \mathrm{~mm}$ and $7.63 \mathrm{~mm}$ in turn compared with the former. It can be seen that with the increase of the elastic modulus of the soil, the reduction of the horizontal displacement of the pile becomes smaller and smaller, and it will eventually reach a fixed value. The bending moment decreases with the increase of the soil elastic modulus. The maximum bending moment decreases from $294 \mathrm{kN} \cdot \mathrm{m}$ to $229.4 \mathrm{kN} \cdot \mathrm{m}$, and the maximum reverse bending moment decreases from -128.3 $\mathrm{kN} \cdot \mathrm{m}$ to $-28.18 \mathrm{kN} \cdot \mathrm{m}$.

2) The influence of the soil elastic modulus in the pile foundation of the high and steep slope bridge on the vertical displacement of the pile foundation is not particularly obvious. For example, when the soil elastic modulus is in the range of $0.25 \mathrm{E}$ to $2 \mathrm{E}$, the vertical displacement of the pile top is $52.01 \mathrm{~mm}, 44.67 \mathrm{~mm}$, $42.49 \mathrm{~mm}, 41.21 \mathrm{~mm}$, and the latter is reduced by $7.34 \mathrm{~mm}, 2.18 \mathrm{~mm}$, and 1.29 $\mathrm{mm}$ in turn compared with the former. Similarly, the vertical displacement of the pile body decreases gradually, and it will eventually reach a fixed value. 
In summary, the elastic modulus of soil of bridge pile foundations on high and steep slopes has a great influence on the deformation and stress characteristics of the pile foundation, and its influence on the horizontal displacement of the pile foundation is much greater than the vertical displacement of the pile foundation. The increase of the soil elastic modulus will reduce the pile displacement, but it will eventually stabilize. Therefore, in actual engineering, when the soil elastic modulus is large, the influence of other factors can be appropriately relaxed. On the contrary, if the soil elastic modulus is small, the bearing performance of the soil needs to be improved.

\subsection{The Influence of Pile Stiffness}

In actual engineering, the design of pile foundation stiffness is a very important link, which determines the safety factor of the entire project. Take the pile stiffness $\mathrm{EI}=0.25 \mathrm{EI}, 0.5 \mathrm{EI}, 1 \mathrm{EI}$ and $2 \mathrm{EI}$, and keep the other parameters unchanged to analyze the influence of the pile stiffness on the pile foundation of the high-steep slope bridge. The pile displacement and bending moment are shown in Figure 16 and Figure 17.

As can be seen from the above picture:

1) The stiffness of the pile has little effect on the horizontal displacement of the bridge pile foundation on a high and steep slope. For example, the maximum horizontal displacement of the pile is $37.91 \mathrm{~mm}, 33.02 \mathrm{~mm}, 29.30 \mathrm{~mm}$ and 26.30 $\mathrm{mm}$ in the range of $0.25 \mathrm{EI}$ to $2 \mathrm{EI}$, the latter is $4.89 \mathrm{~mm}, 3.71 \mathrm{~mm}, 3.00 \mathrm{~mm}$ smaller than the former. Below the buried depth of $3 \mathrm{~m}$, the horizontal displacement of the pile is almost $0 \mathrm{~m}$, and its impact is almost negligible.

2) The stiffness of the pile has a significant effect on the vertical displacement of the bridge pile foundation on a high and steep slope. For example, the maximum vertical displacement of the pile is $145.66 \mathrm{~mm}, 78.36 \mathrm{~mm}, 41.97 \mathrm{~mm}$, $22.99 \mathrm{~mm}$ in the range of $0.25 \mathrm{EI}$ to $2 \mathrm{EI}$, the latter decreased by $67.29 \mathrm{~mm}, 36.39$ $\mathrm{mm}, 18.98 \mathrm{~mm}$ in turn compared with the former. Obviously, as the pile stiffness EI continues to increase, the vertical displacement of the pile will decrease smaller, eventually tends to a fixed value. At the same time, as the stiffness of the pile increases, the bending moment of the pile also decreases significantly. For example, the maximum bending moment is reduced from $1196 \mathrm{kN} \cdot \mathrm{m}$ to 1335 $\mathrm{kN} \cdot \mathrm{m}$, and the maximum reverse bending moment is reduced from $-724.1 \mathrm{kN} \cdot \mathrm{m}$ to $-78.71 \mathrm{kN} \cdot \mathrm{m}$.

In summary, the influence of pile stiffness on the vertical displacement of bridge pile foundations on high and steep slopes is far greater than the horizontal displacement, and as the stiffness of the pile increases, its influence will continue to decrease until the stiffness of the pile is reduced. The influence is negligible. Therefore, in the design of pile foundation engineering, proper pile stiffness should be selected so that the displacement and bending moment of the pile are small, and the stiffness of the pile cannot be increased blindly. This will increase the project budget and cause unnecessary waste. 


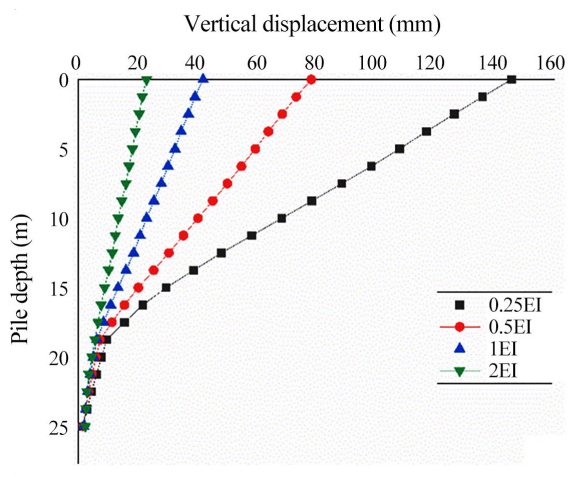

(a) Horizontal displacement

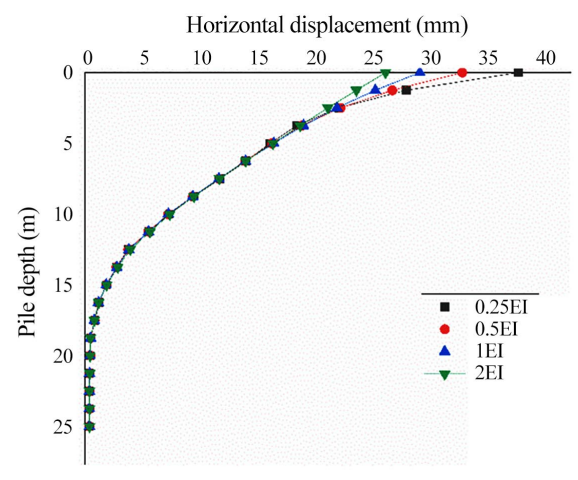

(b) Vertical displacement

Figure 16. Pile displacement under different pile stiffness.

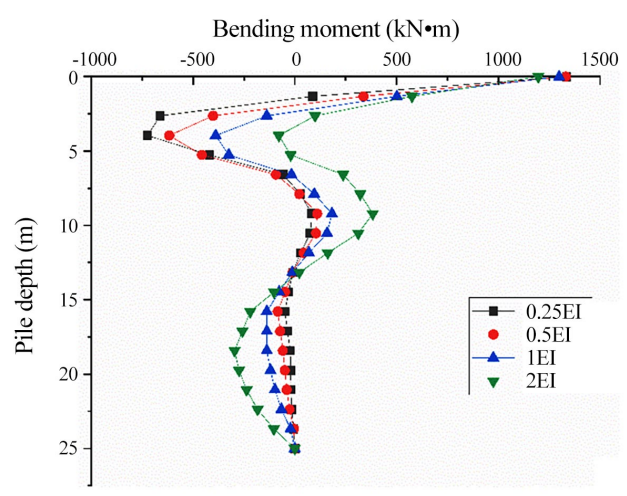

Figure 17. Pile bending moment under different pile stiffness.

\section{Conclusions}

Based on an actual project, this chapter establishes a slope bridge pile foundation model through the finite element software ABAQUS6.14, and analyzes the force and deformation of the pile foundation under vertical, lateral and inclined loads. The influence of the properties of the soil around the pile and the stiffness of the pile on the pile foundation is discussed. The main conclusions are as follows:

1) Under the action of a single vertical load, the vertical displacement of the pile body is relatively large, and it is mainly concentrated near the top of the pile, and the horizontal displacement of the pile body is small. As the pile shaft decreases, the pile side resistance increases to a certain range and tends to be stable.

2) Under the action of a single horizontal load, the horizontal displacement of the pile body is relatively large, mainly in the upper part of the pile body, and the vertical displacement of the pile body is small. The impact of horizontal load on the back pile will be slightly greater than that of the front pile. The maximum bending moment of the pile foundation appears at the top of the pile, and the maximum reverse bending moment appears when the pile length is about $6 \mathrm{~m}$.

3) The pile foundation under the inclined load exhibits an obvious "p- $\Delta$ " effect. The existence of the "p- $\Delta$ " effect makes the horizontal displacement under the inclined load greater than the sum of the horizontal displacements of the two 
loads acting alone. The axial force and bending moment of the pile body show similar laws as the vertical and horizontal loads alone.

4) The nature of the soil around the pile, the stiffness of the pile, and the depth of rock socketing all have different degrees of influence on the pile foundation. The elastic modulus of soil and the stiffness of the pile will mostly reduce the displacement of the pile foundation, but after reaching a certain range, the displacement of the pile foundation will tend to be stable. Therefore, in actual engineering, if the displacement of the pile foundation cannot meet the requirements, the hardness of the soil and the rigidity of the pile should be appropriately increased, but not blindly increased.

\section{Conflicts of Interest}

The authors declare no conflicts of interest regarding the publication of this paper.

\section{References}

[1] Bi, J.H. and Wu, L.Y. (2005) The Dynamic Effect of Train Load on the Slope under the Bridge and Pile Foundation. Chinese Journal of Geotechnical Engineering, No. $12,1458-1462$.

[2] Guo, Y.J, Xie, Y.L., Jiang, L. and Liu, J.H. (2010) Centrifugal Model Test on the Mechanical Characteristics of Slope Pile Foundation. Journal of Chang an University (Natural Science Edition), 30, 35-39.

[3] Lin, P.Z., Wu, F.H. and Yang, Z.J. (2013) Analysis of Mechanical Behavior of Railway Bridge Pier Pile Foundation Considering Slope Effect. Journal of Railway Engineering Society, No. 9, 47-52.

[4] Zhang, Y.J., Li, Y.J., Zhao, M.H., Cao, W.G. and Xie, Z.J. (2014) Design and Calculation Method of Pile Group Foundation under the Action of High and Steep slope. China Journal of Highway and Transport, 27, 84-92.

[5] Feng, Z.J., Wang, H., Wei, J., Gao, X., Jia, Y.W. and Zhang, X. (2015) Model Test Study on Vertical Bearing Characteristics of Bridge Pile Foundation on Loess Gully Slope. Chinese Journal of Geotechnical Engineering, 37, 2308-2314.

[6] Zhao, M.H., Yang, C.W., Chen, Y.H. and Yin, P.B. (2018) Field Test Study on Double-Piled Foundation of Pile-Column Bridge with High and Steep Transverse Slope. Chinese Journal of Geotechnical Engineering, 40, 329-335.

[7] Lin, C., Bennett, C., Han, J., et al. (2010) Scour Effects on the Response of Laterally Loaded Piles Considering Stress History of Sand. Computers and Geotechnics, 37, 1008-1014. https://doi.org/10.1016/j.compgeo.2010.08.009 